\title{
Conclusion: Perspectives on Language, Literacy, and Deafness
}

\author{
Peter V. Paul ${ }^{1, *}$ and Faisl Alqraini ${ }^{2}$ (D) \\ 1 Department of Educational Studies, The Ohio State University, Columbus, OH 43210-1172, USA \\ 2 Department of Special Education, Prince Sattam bin Abdulaziz University, Sa'ad Ibn Mu'adh, \\ Al-Kharj 16278, Saud Arabia; f.alqraini@psau.edu.sa \\ * Correspondence: paul.3@osu.edu
}

Received: 11 November 2019; Accepted: 28 November 2019; Published: 1 December 2019

\begin{abstract}
As indicated in this Special Issue, there has been much debate on the development of English language and literacy in d/Deaf and hard of hearing (d/Dhh) students. Questions remain on the nature of the first language and the relation of this language to the development of English literacy. There is also considerable controversy on the role of English phonology. Adding to the complexity is the increase of $d / D h h$ children for whom English is not the home language and the ongoing challenge of addressing the needs of those with disabilities or additional disabilities. After describing English literacy and the need for documenting desirable research characteristics, the authors of this conclusion article utilize a construct named the Qualitative Similarity Hypothesis (QSH) as the guiding framework for addressing issues such as the role of phonology and the nature of the through-the-air form of the language of print. The QSH asserts that $\mathrm{d} / \mathrm{Dhh}$ students need to master the same set of fundamentals as typical English literacy learners. These fundamentals include code-related, language-related, and comprehension-related skills. One major assertion is that proficiency in the through-the-air form of English is essential for achieving proficiency in conventional English literacy skills. It is argued that the importance of English language proficiency has been emphasized in literacy models that delineate the strong connections among language, reading, and writing, even for second language learners of English or English learners. Another major assertion is that proficiency in English phonology is necessary (albeit not sufficient) for the development of emerging decoding skills. The use of English phonology facilitates the early and advanced literacy comprehension skills. The article concludes with recommendations for additional research, including the understanding of the visual representation of the structure of English, the development of comprehensive English language assessments, and the exploration of literacy-related skills such as decoding and comprehension. Finally, the validity of the QSH also needs to be further investigated.
\end{abstract}

Keywords: d/Deaf and hard of hearing; demography; developmental framework; English language development; English literacy development

\section{Introduction}

The focus of this Special Issue is to present a state-of-the-art rendition of the development of language and literacy in children and adolescents who are $d /$ Deaf and hard of hearing (d/Dhh). The language in question is the acquisition of English; however, a number of findings can be applied to the acquisition of other phonemic-based languages, which function as the majority language of society [1-3]. Typically, the majority language refers to the language of print that is employed in educational and governmental venues and is often considered, formally or informally, as the official language. The written component of the official language is a standardized form, regardless of the dialectical or regional differences of the through-the-air (i.e., spoken or oral) component in various 
sections of a country. It should be acknowledged, however, that, in some countries, the relationship between the through-the-air and written forms is complex, due, in part, to the number of dialectical variations of speech or the encroachment of the influences of other languages on the mainstream society's language form [4,5]; also, see the review in [6], for Arabic as an example).

Confining our emphasis to English, one of the major challenges for d/Dhh children and adolescents is to develop proficiency in literacy (reading and writing) skills in this majority language of society [7-12]. Since the beginning of the 20th century, it has been well documented that many students with severe to profound hearing loss and some with a moderate loss-in the better unaided ear-graduate from high school (after 12-15 years of compulsory education) reading at about a $4^{\text {th }}$ grade level. Albeit this level seems to be improving $[13,14]$, there are still pervasive challenges.

The contributors to this Special Issue have attempted to address the development of language and literacy from several perspectives using either a professional review and/or a meta-analysis format. The complexity of understanding English language and literacy development has increased in light of the growing number of minorities, including immigrants, specifically the number of $d / D h h$ students whose home language is not English—that is, English language learners or English learners [15,16]. Traditionally, other elements of this complexity have often included d/Dhh students with disabilities (or additional disabilities) and those-for whatever reason-who come to school with limited proficiency in any language $[17,18]$. It is also critical to consider the advancement of sophisticated listening technologies and their contributions to the development of language and literacy; this advancement has spawned an evolving demography of $d / D h h$ children and adolescents $[14,19,20]$. Other important areas covered in this Special Issue include the assessment of language and literacy [21] and the influence of inclusion on the development of language and literacy skills [22].

The plan for this concluding article is as follows: First, we discuss the need for researchers to document adequate demographics and other critical background characteristics of the samples in their investigations. Without such information, we argue that it is difficult to proffer evidence-based or effective practices. Equally as important, it is difficult to understand the context of research findings, especially to understand if progress has been made in the development of language and literacy. Then, we argue for the use of a developmental framework as the guiding and comparison barometer for instructional and research endeavors [3,10]. This framework influences our interpretations of some of the assumptions in the works of others in this Issue (e.g., the constructs of fundamentals $[7,9,11,22]$ and modality independence; see $[7,16])$. Next, we provide a description of English literacy with an eye toward the influence of the through-the-air form of a language and code-related skills (e.g., phonological knowledge, phonemic awareness) - two of the most controversial domains in the discussion of language, literacy, and deafness. We also highlight the need for the development of better language and literacy assessments and additional research on marginalized and underrepresented subgroups of the population of d/Dhh children and adolescents (e.g., Deaf with Disabilities, English learners).

We draw on some of the remarks and findings from the other manuscripts in this Special Issue to highlight and even support our assertions. Given the extensive, but not exhaustive, treatments of the nine articles in this issue, there is always a danger of oversimplification of the contributors' major points. We make no claim that our rendition is the only or best interpretation; our intent is to encourage further dialogue and research regardless of the controversies associated with specific research approaches or topics or with the interpretations of the findings. We conclude our discussion with recommendations for further inquiry with the hope of continuing efforts to close the achievement gap between $\mathrm{d} / \mathrm{Dhh}$ students and their typical language-literacy counterparts.

\section{Demography and Critical Research Characteristics}

One of the quality indicators for an adequate research design is the documentation of demographic and other background characteristics of the sample under study. It is important to contextualize the representativeness of the sample to avoid or minimize generalizations to dissimilar populations 
(e.g., see discussions in $[23,24])$. Inadequate descriptions of the samples undermine the reliability and validity of selected or developed assessments, especially if previous research is being used to justify the use of such assessments. There is little doubt that individual factors can affect the construction and use of assessments and the validity of comparing group performances [23,25]. This not only emphasizes the importance of demography, but also asserts its need for the proffering of reliable and valid evidence-based practices [24].

As noted by Paul and Wang [24], there is considerable debate on what constitutes adequate demographic and background information for $\mathrm{d} / \mathrm{Dhh}$ participants. Controversial demographics include information on hearing acuity (e.g., unaided and aided, age at onset of hearing loss) and speech acuity (e.g., speech discrimination, speech recognition). There may be less controversy on the mode of communication, language use, and presence of additional disabilities-albeit, documenting the accuracy of such information is a challenge for investigators (e.g., [18,21]). In any case, to understand the effects of interventions or even the use of early amplification such as cochlear implants and digital hearing aids, there needs to be a better documentation of the extent, length, and use of these variables [14].

Related to the domain of language and literacy development-and the source of controversy regarding demographics-is the proposition that there might be two distinct groups of $\mathrm{d} / \mathrm{Dhh}$ individuals [26-28]. The line of demarcation for this distinction is dependent on the assessment of the adequate use of functional hearing with or without amplification. That is, one group may be able to access and understand "running speech" whereas the other group cannot perform this task adequately. It has been hypothesized that $\mathrm{d} / \mathrm{Dhh}$ individuals who primarily use a signed language, or even a form of signing and have limited or nonfunctional hearing, perform differently than the group that can access and understand running speech. The psychological reality of this distinction provides support for understanding the effects of the use of a signed language in the development of English literacy skills [16,29]. At the least, this differentiates the role of through-the-air language and the use of code-related skills-constructs to be discussed later. For example, proponents of this distinction highlight the notion of a "visual phonology" of a signed language, particularly within an American Sign Language (ASL)/English print-sign bilingual program [30]. This view contrasts with those of others $[7,9,11]$, who argue that not only is a sound phonology necessary for early and conventional literacy development, but also that functional hearing is not the major issue in understanding the development of English literacy comprehension. Obviously, a diverse set of attributes of the participants need to be considered, but language proficiency and code-related skills seem to command a substantial amount of attention (e.g., see discussions in [10,31,32]).

\section{The Qualitative Similarity Hypothesis}

It has been argued that $\mathrm{d} / \mathrm{Dhh}$ students follow a developmental learning trajectory that is similar to that of typical literacy learners-albeit some students will proceed at a slower quantitative rate due to a number of variables such as the quality of interventions, effectiveness of early amplification, variability in teacher competency, and so on $[7,9,11,19,22]$. This phenomenon, coined the Qualitative Similarity Hypothesis (QSH) asserts that, regardless of the degree of hearing acuity, $\mathrm{d} / \mathrm{Dhh}$ students need to acquire proficiency in the same group of fundamentals associated with code-related, language-related (e.g., English language proficiency), and comprehension-related skills that are necessary for the development of typical literacy skills $[8,10,33]$. It is important to remember that variations in the learning trajectory of $\mathrm{d} / \mathrm{Dhh}$ students do not mean that the developmental trajectory is "different" because this difference is associated with the rate of acquisition, not with the developmental or qualitative aspects of the learning process.

A similar version of the QSH has been documented in the broader research literature for "hearing" English learners and those who are at-risk or have disabilities [1,3,34]. That is, the acquisition of English by English learners or those with disabilities is developmentally similar to that of native language and literacy learners of English. Taken together, it can be argued that the general findings of literacy 
acquisition for typical hearing English learners can or should be applied to d/Dhh students and other students with disabilities as well as to English learners (i.e., English is not the native or home language). In addition, these findings can or should be applied to $\mathrm{d} / \mathrm{Dhh}$ students who are English learners and those who have disabilities such as cognitive disabilities and autism. Nevertheless, there are challenges in understanding the language and literacy development of these subgroups of $\mathrm{d} / \mathrm{Dhh}$ children and adolescents $[18,21]$. Whether the development of these latter subgroups is "developmentally different" from that of typical literacy learners is in need of additional research.

In our view, the QSH should be the guiding framework or "prism" through which the findings and conclusions of most other articles in this Special Issue, indeed, of all research on English literacy and d/Dhh children and adolescents, should be evaluated. Granted, the QSH is a "framework" and it is critical to conduct additional research on the various components or constructs (e.g., phonological awareness, etc.) within this framework (e.g., $[10,11,35])$. There are ongoing debates on the nature and extent of these constructs for the development of reading in all $\mathrm{d} / \mathrm{Dhh}$ learners with attention, as mentioned previously, focused on English phonology and the role of through-the-air language use $[11,36,37]$. Nevertheless, it has been argued that there is no strong evidence to suggest that the fundamentals of literacy should be different for $\mathrm{d} / \mathrm{Dhh}$ students or even for any student attempting to develop an adequate level of proficiency in English language and literacy for age-level acquisition $[7,9,11,22]$. It is argued that the QSH is modality independent, as mentioned by several contributors to this Special Issue (notably, $[7,16]$ ). Essentially, this means that it applies only to d/Dhh individuals who have adequate access to functional hearing or running speech (one of the two distinct groups mentioned previously in the section above on demography). However, we agree with the argument of others in this issue $[7,9,11,22]$ that this does not alter the fundamentals of the development of English reading and writing - and we assert that the QSH is not modality independent.

Regardless of the strength of the research support for the QSH, we acknowledge that it is still important to differentiate instruction, especially considering the wide range of variability in individual profiles in the population of $\mathrm{d} / \mathrm{Dhh}$ children and adolescents (see $[7,16,18,21])$. This range includes factors such as age levels, family backgrounds, presence of disabilities, demands of the reading tasks and instruction, and the results of specific components of reading via the use of assessments. Addressing whether literacy acquisition is similar or different is critical for the development of evidence-based or effective practices, which seems to be lacking or relatively little is available for $\mathrm{d} / \mathrm{Dhh}$ students (see review in [38]). Assuming that we have a consensus on the various aspects of the QSH, then the next step might be to ascertain the manner in which to improve the literacy level of students (see [7]).

\section{English Literacy}

To contextualize the QSH and understand the challenges of developing English language and literacy in d/Dhh individuals requires an understanding of the overall construct of English literacy, particularly the acquisition process $[8,10,39]$. In essence, the manner in which literacy is defined or even measured impacts the accuracy of the documented achievement level or even the proffering of effective or evidence-based instructional practices for $\mathrm{d} / \mathrm{Dhh}$ students. There is no shortage of theoretical models that purport to represent the overall constructs of English language or literacy or the various components (i.e., subconstructs, processes) associated with these overall constructs (e.g., [39-41]). The number of influential subconstructs (e.g., phonemic awareness, vocabulary, fluency, prior knowledge, metacognition) that are involved makes it challenging to describe not only the overall nature of the literacy acquisition process, but also what might be needed (e.g., evidence-based or facilitative practices) to develop literacy proficiency in struggling readers and writers.

One common approach to developing a working literacy model has been to conduct research and interpret findings on the struggles or challenges of various cohorts of children, including those with disabilities or are at-risk, in the development of skills from the emergent to the conventional literacy period (e.g., see reviews in [33,39,42-44]). One framework for understanding these challenges, especially for $\mathrm{d} / \mathrm{Dhh}$ students $[10,35,45]$, has been to relate the results to the general findings of 
the National Reading Panel [46] and the National Early Literacy Panel [47]. This suggests that the acquisition of English literacy for all literacy learners requires proficiency in a common set of fundamentals and adheres (or should adhere) to a similar developmental trajectory (albeit, at a slower rate for a number of struggling literacy learners).

It is possible to delineate the common components of extant English reading models, which should include, at the least, through-the-air English language proficiency (including vocabulary knowledge), code-related (e.g., phonemic awareness, letter-sound relations) plus comprehension (e.g., prior knowledge, metacognition, inferential) skills. Other factors may include sociocultural variables such as the influence of the home environment, teacher-student interactions, and teacher competency (also, see [22] for a discussion of the effects of inclusion). A substantial amount of attention has been paid to sociocultural factors. However, it should be kept in mind that "A sociocultural perspective on children with reading disabilities does not discount other explanations for reading failure or other recommendations for instruction ([48] (p. 54)). In addition, it is also doubtful that all or most of the reading difficulties of children and adolescents can be explained by appealing to factors associated with ethnicity, race, or gender $[10,49]$.

There are literacy models that seem to be comprehensive- -that is, covering cognitive, psychological, and ecological domains (e.g., Componential Model of Reading, [50]). These models also assert the nonlinearity and non-hierarchical elements of the reading process. Then there are models that are linear and hierarchical and focus mostly on decoding and language comprehension skills (e.g., Convergent Skills Model of Reading, [51], Simple View of Reading, [52]). Despite the disadvantages or limitations of proffering models, they do provide a venue for researching and understanding the literacy process. More important, as noted by the National Reading Panel [46] and the National Early Literacy Panel [47], and as mentioned previously, there may be fundamentals that apply to all children attempting to learn to read and write in English. The National Reading Panel proposed fundamentals such as the use of phonics (for letter-sound relations), phonemic awareness, fluency, vocabulary, and text comprehension. Implicit in these fundamentals is proficiency in the receptive and expressive use of through-the-air English, which is the language of print.

In general, English reading is defined as obtaining information or meaning from print (i.e., constructing meaning), and English writing can be defined as putting information down in print (i.e., composing meaning). We agree with Mayer that proficiency in English writing requires a level of proficiency in English reading, albeit the two constructs are related and may have reciprocal influences (see [9]). In addition to sociocultural factors mentioned above and for the purpose of this article, we use an equation to describe English reading as follows:

English reading [comprehsion] = English language comprehension/competency (through-the-air mode) + code-related skills + comprehension skills (e.g., vocabulary, prior knowledge, metacognition).

Although all areas are discussed briefly here, our major foci in the ensuing sections are language proficiency and the controversial area of code-related skills, which are also discussed in several articles in this Special Issue (e.g., $[7,9,11,16,29])$.

\subsection{Language Proficiency}

As mentioned previously, one of the controversial and oft-discussed domains of understanding the development of English literacy is the role that language plays in this development. Research that has focused predominantly on the development of language or language/communication difficulties often devote some space to the relationship between through-the-air language and the language of print-that is literacy (e.g., [53,54]). With respect to d/Dhh children and adolescents, the controversy centers on the nature and extent of the through-the-air form.

Scott and Dostal [29] reviewed, in part, the literature on the development of language and its effects on English literacy, utilizing two broad domains: natural languages (e.g., American Sign Language and English) and communication systems (e.g., a form of English sign, cued speech/language). We agree with their findings that there might be stronger evidence for natural languages as opposed to the 
communication systems, particularly the sign communication systems. We argue, however, that the bulk of the evidence for the beneficial relations between ASL and English literacy is mostly correlational (also see [10]), but is certainly worthy and in need of further research. In our view, a better understanding of the effects of ASL on the development of English literacy requires a better understanding of the manner in which code-related skills are acquired-the use of visual phonology notwithstanding (discussed later). That is, in our view, it is critical to understand how $\mathrm{d} / \mathrm{Dhh}$ children and adolescents can acquire the "structure" of English (phonology, morphology, syntax) via the use of ASL, especially beyond the emergent English literacy stage.

There is little doubt regarding the problematic nature of the use of the sign communication systems (also see $[55,56]$ ). The descriptions of the sign systems are arbitrary and idealized with respect to their representations of English. These systems are purported to represent English morphology and syntax in a visual manner and are supposed to be executed in conjunction with speech. This "simultaneous" presentation purports to cover, at least, the phonology of English, considering that phonology is the building block of any language. As argued by LaSasso, Crain, and Leybaert [55], this representation, particularly by practitioners, results in a degraded inadequate representation of English. The level of success with the use of sign communication is contingent on the individual's ability to access the structure of English, specifically the phonological and morphological components. Nevertheless, LaSasso et al.'s degraded hypothesis certainly lends support to the existence of language deprivation $[16,29]$ and the need to address this serious concern for a number of $d / D h h$ children and adolescents.

This degraded representation by any sign communication system led LaSasso et al. [55] to proffer Cued Speech/Language as the most viable, complete communication system for representing English. As noted by Scott and Dostal [29] and others (e.g., [20,57]), there is some evidence for the effectiveness of Cued Speech/Language for the development of English phonology. More important, as emphasized by Scott and Dostal [29], there is a need for intervention research in both domains-natural language and communication systems.

Understanding the effects of a signed language on the development of English literacy is critical; however, such research needs to consider the prevailing findings of the nature of the through-the-air form that facilitates the development of English literacy for typical literacy learners. For example, Kamhi and Catts [43] argued that:

Knowledge of the similarities and differences between spoken language and reading is critical for understanding how children learn to read and why some children have difficulty learning to read. ([43], (p. 1)).

The assumption here is that proficiency in the through-the-air form of English is essential for achieving proficiency in conventional English literacy skills.

On one hand, the National Early Literacy Panel [47] found oral language (i.e., through-the-air language; cf. [58]) to be a weak predictor of later decoding and reading comprehension abilities. However, Storch and Whitehurst [59], also discussed in Mayer and Trezek [8], found that oral language skills contributed directly to reading abilities in grades 3 and 4 . By the later elementary school grades (4th-6th grade), research has demonstrated that "hearing" children's vocabulary knowledge and reading comprehension is strongly correlated with through-the-air language abilities developed during the early years (e.g., $[1,46,60])$. Whether these findings also apply to $\mathrm{d} / \mathrm{Dhh}$ children and adolescents is in need of further research - albeit, there has been much discussion of the inadequate English language development of these individuals (e.g., $[10,56,61])$.

This focus on language proficiency, specifically language comprehension skills, is a major component of linear, hierarchical literacy models. For example, Trezek and Mayer [11] seem to favor the Simple View of Reading, which proposed an equation such as Decoding (D) X Language Comprehension $(\mathrm{C})=$ Reading Comprehension $(\mathrm{R})$. That is, reading comprehension is dependent on adequate decoding and language comprehension skills. Language comprehension is taken to mean an understanding of the use of language (i.e., linguistic information), in this case English, through oral 
language or, in the parlance here, through-the-air. As stated by Trezek and Mayer [11], the learner can use language to interpret words and sentences and also to develop an overall meaning model of the text. It can be assumed that adequate receptive and expressive skills in English facilitates the acquisition of reading comprehension, but-of course-it is not sufficient as other skills are needed. Language proficiency here means proficiency in all components of English (phonology, morphology, syntax, semantics, pragmatics) as well the integration and use of these components for receptive and expressive communication.

The importance of English language proficiency is also discussed in literacy models that stress the strong connections among English language, reading, and writing, even for second language learners of English or English learners [1,9,62-65]. Mayer and Trezek [9] discussed a model named the Simple View of Writing (SVW), which seems to parallel the construct, Simple View of Reading. The SVW seems to highlight both the product (transcription) and process (ideation) of composition. The product component needs to be automatic (analogous to word identification) so that the process can be generated. The point here is that oral (through-the-air) language drives this operation, and English oral language is the better facilitator of English written language.

In addition to the above, communicative, through-the-air language proficiency is strongly related to the development of academic language. Academic language refers to the metalanguage or specialized vocabulary that is often found in literacy materials in content areas such as social studies, science, and mathematics (for deafness, see [66]). Academic language is influenced by the construct of cultural literacy.

Cultural literacy is familiarity with and the ability to understand the idioms, allusions, and informal content that create and constitute a mainstream culture. From familiarity with street signs to knowledge of historical references to understanding slang and figurative language use; the literacy process demands interactions with the culture and reflections on the contents. Cultural literacy requires familiarity with a broad range of general knowledge and implies the use and sharing of that knowledge-for example, terms associated with the culture of American society's foundations such as the American Revolution, slavery, bottom-line, market-driven economy, and others [67].

\subsection{Code-Related Skills}

Code-related skills are associated with decoding and encoding print such as print awareness and phonological processing principles $[46,47,59,68-71]$. Print awareness is necessary for progress with vocabulary and reading development. Children need to understand what is meant by reading-for example, there is information on the page. They also need to understand the basic relationship between oral language and printed language. Print awareness skills include the following:

1. Concepts of text features or print, such as letter, word, sentence, question, or dialogue.

2. Vocabulary for discussing books, such as cover, page, story, character, title (name), author (writer), and illustrator (artist).

3. How to handle books, such as holding right side up, turn pages, where to begin reading, attend to the spaces in the text, reading from left to right and top to bottom.

4. Book structures, such as title page, chapters, and table of contents.

Phonological processing skills refer to the concepts of sensitivity, memory, and naming. The ability to detect and manipulate the phonemes (sounds) of a language (e.g., blending and segmenting) entails phonological sensitivity. Holding auditory information in short-term memory (e.g., repeating nonsense words, words, or sentences) refer to phonological memory, and this ability is strongly related to adequate comprehension of sentences (i.e., syntactic structures) for $\mathrm{d} / \mathrm{Dhh}$ children and adolescents (see reviews in [56,72]). Phonological memory, along with rapid automatic naming (RAN), has been associated with the ability to rapidly retrieve a sufficient amount of phonological information associated with letters and words for the development of fluent, automatic decoding and encoding skills [46,47]; for d/Dhh learners, see [11,56,72]. Alphabetic knowledge such as letter name knowledge, letter sound 
knowledge, letter name fluency, and letter writing is also related to emergent literacy skills, especially for typical and struggling literacy learners (e.g., [73]).

There is little debate regarding the importance of developing print awareness skills in $\mathrm{d} / \mathrm{Dhh}$ children (see reviews in $[10,35]$ ). However, there is considerable controversy on the role of a sound phonology for the development of English literacy skills [10,11,29,31,32]. Much of the research evidence suggests that the better $\mathrm{d} / \mathrm{Dhh}$ literacy users have an adequate command/understanding of domains such as phonemic awareness and sound-letter correspondences, which provide the foundations for accessing the alphabetic writing system for facilitating the more advanced development of English literacy skills (see review in [74]). Research has also documented a high correlation between phonological skills and vocabulary ([74,75]; cf. [37]).

There is also evidence that $\mathrm{d} / \mathrm{Dhh}$ learners can benefit from phonological awareness interventions [8,20], especially via the use of Visual Phonics ([38,76,77]; also see discussion in [29]). Even Cued Speech/Language has been demonstrated, as a communication method, for developing decoding skills in d/Dhh literacy learners ([20,55], also see discussion in [29]). Trezek [20] documented the contributions of Cued Speech/Language to the development of phonological and early reading abilities. She concluded that the benefits of Cued Speech/Language occurred despite the documentation of varying levels of hearing loss and even varying levels of speech intelligibility. Trezek reported beneficial effects on domains such as phonological awareness, phonemic awareness, alphabet knowledge, and phonological memory.

On the other hand, there is some evidence for the use of a visual phonology from a signed language (e.g., American Sign Language) for the development of early English literacy skills (e.g., [26,28]; also see related discussions in [16,29]). This line of research seems to question the necessary role of phonological processes based on sound (i.e., English phonology). This construct also seems to apply mostly to a cohort of d/Deaf children, who are bilingual, involving the use of American Sign Language (ASL), fingerspelling, and the print form (i.e., orthography) of English, labeled sign-print bilingualism. Whether this combination of processes should also be used for $\mathrm{d} / \mathrm{Dh}$ children who are limited users of English, coming from English-speaking homes, is open to question (see [16]; also see related discussion in $[10,56])$.

Support for the use and benefits of a visual phonology is motivated, in part, by the issue of hearing acuity ([26,28]; also see related discussions in [78,79]). That is, visual phonology (in conjunction with fingerspelling and English orthography) seems to be the most efficient route for developing English literacy skills in $\mathrm{d} / \mathrm{Dhh}$ children with minimal or no functional access to audition with or without amplification, especially during the first few years of life with emerging literacy skills. In essence, researchers advocating visual or sign phonology have emphasized the role of visual perceptual processes for the early foundational stage in accessing words. Allen et al. [26] proffer a modality independent hypothesis, which asserts that English decoding skills can be developed via either an auditory-based (sound) or visual-based phonology. Thus, in their view, the phonological component of the Qualitative Similarity Hypothesis [10] pertains only to d/Dhh individuals with adequate access to audition with or without amplification. For d/Dhh individuals with limited or no access, a visual-based or sign phonology is a comparable alternative.

Whether a visual-based or sign phonology is analogous to a sound-based phonology, particularly one that is germane to accessing print words, is an open question (see discussions in $[78,79]$ ). There is ample research that sound-based phonological processors need to work in tandem with orthographic processors for developing rapid automatic word identification skills (e.g., [68]). In addition, this combination is most effective for developing advanced English literacy skills, at least in "hearing" literacy or struggling literacy learners. Allen et al. [26] and others [28] seem to argue that the phonological and orthographic processors do not need to be associated with the same language of print for accessing English words.

We favor the interpretations of Mayer and Trezek [9,11] that ASL can be "supportive" in developing or understanding information. However, to construct the meaning of English texts or compose passages 
in English, ASL (even with other components such as fingerspelling and English orthography) may not be sufficient beyond the emergent or early English literacy phase. In essence, the role of a sound phonology is necessary, but not sufficient, for the development of decoding skills and facilitating early and advance English literacy comprehension skills. This can be achieved either via the typical route (adequate hearing for accessing spoken or through-the-air English) or alternative routes such as Visual Phonics or Cued Speech/Language. Our view comports with that of Mayer and Trezek [80]:

While it is true that those who adopt the view that learning to read is a qualitatively or developmentally similar process whether one is deaf or hearing (i.e., the view that phonology is necessary) do emphasize control of spoken language as being the most expedient route for learning to decode, they also suggest that this proficiency may also be achieved through other modalities (i.e., via a visual communication system such as Cued Speech or a visual-tactile tool such as Visual Phonics) that stand in for phonological representations and realize the same outcomes (i.e., mastery of sound-symbol correspondences). ([80], (p. 367))

\section{Emerging Trends and Issues}

Previously, we have mentioned the need for researchers to document adequate demographics for understanding the development of language and literacy for varying cohorts of $\mathrm{d} / \mathrm{Dhh}$ children and adolescents. In fact, due to early intervention and early amplification and, possibly, inclusive practices (see [22]), the cohorts of $\mathrm{d} / \mathrm{Dhh}$ individuals have been evolving, and language and literacy achievement has improved (e.g., $[10,14,81])$. Paul et al. [10] argued that there has been two broad phases with a third emerging phase. One phase entails the period up to the advent of modern amplification systems such as the use of digital hearing aids and cochlear implants. The second phase can be considered the current one, covering the past 30 years. The emerging third phase entails the effects of wide-spread applications of early intervention and early amplification, which may positively affect the current levels of English language and literacy development-albeit, there have already been documented improvements (e.g., $[10,13,14,20,82])$.

The effects of early intervention, early amplification, and inclusive practices need to be contextualized with respect to demography and other background variables. For example, Mayer and Trezek [14] highlighted this issue in their review of studies on $\mathrm{d} / \mathrm{Dhh}$ children who are users of cochlear implants. Mayer and Trezek [14] reported that there are encouraging positive findings of achievement; nevertheless, there is considerable variability within the studies due to the lack of documentation of demographics and other critical information such as length of use, maintenance, age at implantation, and so on. Interestingly, it might be that the use of signed communication in children with cochlear implants can support the development of English during the early years; however, this variable needs to be adequately documented. As discussed previously, the documentation of adequate information on participants is necessary for the eventual proffering of evidence-based practices for the varying cohorts of $\mathrm{d} / \mathrm{Dhh}$ children and adolescents.

\section{Summary}

Each contributor in this Special Issue proffered recommendations for further research on the acquisition of language and literacy skills, specifically with respect to ASL, bilingualism, inclusion, English reading and writing, assessment, and amplification systems. Given the limited evidence-based data on d/Dhh children, we argue that an understanding of the acquisition of English language and literacy skills by typical literacy learners should be the reference for developing such skills in $\mathrm{d} / \mathrm{Dhh}$ children. This is true, regardless of the level of English proficiency or type of first-language in the homes of these children. This is the underlying principle of the Qualitative Similarity Hypothesis. Of course, it is still important to conduct additional research on $\mathrm{d} / \mathrm{Dhh}$ children and adolescents to refine the typical instructional guidelines. In fact, it is clear that instructional strategies need to be differentiated according to the individual profiles of $\mathrm{d} / \mathrm{Dhh}$ students.

In our view, there is a need to conduct research on $\mathrm{d} / \mathrm{Dhh}$ children in the preschool to Grade 2 range and to ascertain the contributions of code-related constructs to reading-related comprehension tasks for 
various cohorts of $\mathrm{d} /$ Deaf students in the later elementary grades up to and including the middle school level (e.g., Grades 3 to 8). Research is also needed to understand the development of other literacy-related components such as through-the-air English language and vocabulary, and comprehension factors such as inferencing, prior knowledge, and metacognition. Future researchers need to develop language and literacy assessments that focus specifically on a non-unitary model of acquisition. A non-unitary model asserts that there is not one all-encompassing factor that accounts for the development of complex skills such as language and literacy.

There are a number of lingering issues that need to be resolved if we intend to develop evidence-based practices for the development of English language and literacy skills in d/Dhh children and adolescents. The list below is not exhaustive, but represents a few of the major domains.

- Understanding what it means to adequately represent the form or structure of English, including phonology and morphology, in a visual modality (e.g., in sign systems, Cued Speech/Language).

- Addressing the inconsistent use (i.e., execution or production) of the English sign systems by practitioners, due to the cumbersomeness and the difficulty of speaking and signing simultaneously.

- Exploring the learnability of the sign systems and skills such as speech and speech reading.

- Studying the effects of varying cognitive or social factors such as working memory capacity, motivation or interest, teacher-learner interactions, impoverished or disadvantaged home situations.

- Developing and using a range of assessments for through-the-air English language proficiency.

- Exploring metacognitive and other self-regulatory effects on English language and literacy acquisition.

- Within the framework of the QSH, exploring the contributions of specific code-related (e.g., phonemic awareness), language-related (e.g., morphology), and comprehension-related (e.g., inferencing, prior knowledge) skills of $\mathrm{d} / \mathrm{Dhh}$ literacy learners and comparing these contributions to those of typical literacy learners. Another approach is to test hypotheses within the Simple View of Reading, which would permit an evaluation of the QSH [11].

In summary, it is hoped that the information presented in this Special Issue contributes to the further dialogue and development of theory, research, and practice. Subsequently, this should lead to the proffering of evidence-based practices for the improvement of English language and literacy skills for d/Dhh children and adolescents.

Author Contributions: Conceptualization and writing of original draft, P.V.P.; writing—review and editing, P.V.P., F.A.

Funding: This research received no external funding.

Conflicts of Interest: The authors declare no conflict of interest.

\section{References}

1. Connor, C.M.; Alberto, P.A.; Compton, D.L.; O'Connor, R.E. Improving Reading Outcomes for Students with or at Risk for Reading Disabilities: A Synthesis of the Contributions from the Institute of Education Sciences Research Centers (NCSER 2014-3000); National Center for Special Education Research, Institute of Education Sciences, U.S. Department of Education: Washington, DC, USA, 2014. Available online: http://ies.ed.gov/ (accessed on 21 February 2019).

2. Seymour, P.H.K. Theoretical framework for beginning reading in different orthographies. In Handbook of Orthography and Literacy; Joshi, R.M., Aaron, P.G., Eds.; Erlbaum: Mahwah, NJ, USA, 2006; pp. 441-462.

3. Stanovich, K.E. Progress in Understanding Reading: Scientific Foundations and New Frontiers; The Guilford Press: New York, NY, USA, 2000.

4. Crystal, D. The Cambridge Encyclopedia of Language, 2nd ed.; Cambridge University Press: New York, NY, USA, 1997.

5. Crystal, D. How Language Works; Penguin: London, UK, 2006. 
6. Saiegh-Haddad, E.; Joshi, R.M. (Eds.) Handbook of Arabic Literacy: Insights and Perspectives; Springer: New York, NY, USA, 2014.

7. Hartman, M.C.; Nicolarakis, O.D.; Wang, Y. Language and literacy: Issues and considerations. Educ. Sci. 2019, 9, 180. [CrossRef]

8. Mayer, C.; Trezek, B.J. Early Literacy Development in Deaf Children; Oxford University Press: New York, NY, USA, 2015.

9. Mayer, C.; Trezek, B.J. Writing and deafness: State of the evidence and implications for research and practice. Educ. Sci. 2019, 9, 185. [CrossRef]

10. Paul, P.V.; Wang, Y.; Williams, C. Deaf Students and The Qualitative Similarity Hypothesis: Understanding Language and Literacy Development; Gallaudet University Press: Washington, DC, USA, 2013.

11. Trezek, B.J.; Mayer, C. Reading and deafness: State of the evidence and implications for research and practice. Educ. Sci. 2019, 9, 216. [CrossRef]

12. Williams, C.; Mayer, C. Writing in young deaf children. Rev. Educ. Res. 2015, 85, 630-666. [CrossRef]

13. Easterbrooks, S.R.; Beal-Alvarez, J. States' reading outcomes of students who are d/Deaf and hard of hearing. Am. Ann. Deaf 2012, 157, 27-40. [CrossRef]

14. Mayer, C.; Trezek, B.J. Literacy outcomes in deaf students with cochlear implants: Current state of the knowledge. J. Deaf Stud. Deaf Educ. 2018, 23, 1-16. [CrossRef]

15. Cannon, J.E.; Guardino, C.; Gallimore, E. A new kind of heterogeneity: What we can learn from d/Deaf and hard of hearing multilingual learners. Am. Ann. Deaf 2016, 161, 8-16. [CrossRef]

16. Howerton-Fox, A.; Falk, J.L. Deaf children as 'English learners': The psycholinguistic turn in deaf education. Educ. Sci. 2019, 9, 133. [CrossRef]

17. Guardino, C.; Cannon, J.E. Theory, research, and practice for students who are deaf and hard of hearing with disabilities: Addressing the challenges from birth to postsecondary education. Am. Ann. Deaf 2015, 160, 347-355. [CrossRef]

18. Nelson, C.; Bruce, S.M. Children who are deaf/hard of hearing with disabilities: Paths to language and literacy. Educ. Sci. 2019, 9, 134. [CrossRef]

19. Holt, R.F. Assistive hearing technology for deaf and hard-of-hearing spoken language learners. Educ. Sci. 2019, 9, 153. [CrossRef]

20. Trezek, B.J. Cued speech and the development of reading in English: Examining the evidence. J. Deaf Stud. Deaf Educ. 2017, 22, 349-364. [CrossRef] [PubMed]

21. Pizzo, L.; Chilvers, A. Assessment of language and literacy for children who are d/Deaf and hard of hearing. Educ. Sci. 2019, 9, 223. [CrossRef]

22. Alasim, K. Reading development of students who are deaf and hard of haering in inclusive education classrooms. Educ. Sci. 2019, 9, 201. [CrossRef]

23. Council for Exceptional Children. Council for Exceptional Children standards for evidence-based practices in special education. Except. Child. 2014, 80, 504-511. [CrossRef]

24. Paul, P.V.; Wang, Y. Publishing in refereed journals: Unpacking a few salient reporting standards. In Research in Deaf Education: Contexts, Challenges, and Considerations; Cawthon, S.W., Garberoglio, C.L., Eds.; Oxford University Press: New York, NY, USA, 2017; pp. 341-360.

25. Odom, S.L.; Brantlinger, E.; Gersten, R.; Horner, R.H.; Thompson, B.; Harris, K.R. Research in special education: Scientific methods and evidence-based practices. Except. Chidren 2005, 71, 137-148. [CrossRef]

26. Allen, T.E.; Letteri, A.; Choi, S.H.; Dang, D. Early visual language exposure and emergent literacy in preschool deaf children: Findings from a national longitudinal study. Am. Ann. Deaf 2014, 159, 346-358. [CrossRef]

27. Easterbrooks, S.R.; Lederberg, A.; Antia, S.; Schick, B.; Kushalnagar, P.; Webb, M.Y.; Branum-Martin, L.; Connor, C.M. Reading among diverse DHH learners: What, how, and for whom? Am. Ann. Deaf 2015, 159, 419-432. [CrossRef]

28. McQuarrie, L.; Parrila, R. Literacy and linguistic development in bilingual Deaf children: Implications of the "and" for phonological processing. Am. Ann. Deaf 2014, 159, 372-384. [CrossRef]

29. Scott, J.A.; Dostal, H.M. Language development and deaf/hard of hearing children. Educ. Sci. 2019, 9, 135. [CrossRef]

30. Wolsey, J.-L.A.; Clark, M.D.; Andrews, J.F. ASL and English bilingual shared book reading: An exploratory intervention for signing deaf children. Biling. Res. J. 2018, 41, 221-237. [CrossRef] 
31. Wang, Y.; Andrews, J. Reading and deaf individuals: Perspectives on the qualitative similarity hypothesis. Am. Ann. Deaf 2014, 159, 319-322. [CrossRef] [PubMed]

32. Andrews, J.; Wang, Y. The qualitative similarity hypothesis: Research synthesis and future directions. Am. Ann. Deaf 2015, 159, 468-483. [CrossRef] [PubMed]

33. Paul, P.; Wang, Y. Literate Thought: Understanding Comprehension and Literacy; Jason \& Bartlett Learning: Sudbury, MA, USA, 2012.

34. Cain, K.; Oakhill, J. (Eds.) Children's Comprehension Problems in Oral and Written Language; Guilford Press: New York, NY, USA, 2007.

35. Wang, Y.; Williams, C. Are we hammering square pegs into round holes? An investigation on the meta-analyses of reading research with students who are $\mathrm{d} /$ Deaf or hard of hearing and students who are hearing. Am. Ann. Deaf 2014, 159, 323-345. [CrossRef]

36. Allen, T.; Clark, M.D.; del Giudice, A.; Koo, D.; Lieberman, A.; Mayberry, R.; Miller, P. Phonology and reading: A response to Wang, Trezek, Luckner, and Paul. Am. Ann. Deaf 2009, 154, 338-345. [CrossRef]

37. Luft, P. Reading comprehension and phonics research: Review of correlational analyses with deaf and hard of hearing students. J. Deaf Stud. Deaf Educ. 2018, 23, 148-163. [CrossRef]

38. Trezek, B.J.; Wang, Y. Evaluating evidence-based practices in reading interventions for deaf students. In Research in Deaf Education: Contexts, Challenges, and Considerations; Cawthon, S.W., Garberoglio, C.L., Eds.; Oxford University Press: New York, NY, USA, 2017; pp. 277-308.

39. Alvermann, D.E.; Unrau, N.J.; Ruddell, R.B. (Eds.) Theoretical Models and Processes of Reading, 6th ed.; International Reading Association: Newark, DE, USA, 2013.

40. Israel, S.; Duffy, G. (Eds.) Handbook of Research on Reading Comprehension; Routledge: New York, NY, USA, 2009.

41. Joshi, R.M.; Aaron, P.G. (Eds.) Handbook of Orthography and Literacy; Erlbaurm: Mahwah, NJ, USA, 2006.

42. Arfe, B.; Dockrell, J.; Berninger, V. (Eds.) Writing Development in Children with Hearing Loss, Dyslexia, or Oral Language Problems: Implications for Assessment and Instruction; Oxford University Press: New York, NY, USA, 2014.

43. Kamhi, A.; Catts, H. Language and Reading Disabilities, 3rd ed.; Pearson Education: Boston, MA, USA, 2012.

44. McGill-Franzen, A.; Allington, R. (Eds.) Handbook of Reading Disability Research; Routledge: New York, NY, USA, 2011.

45. Trezek, B.J.; Wang, Y.; Paul, P.V. Reading and Deafness: Theory, Research, and Practice; Delmar/Cengage Learning: Clifton Park, NY, USA, 2010.

46. National Reading Panel. Report of the National Reading Panel: Teaching Children to Read-An Evidence-Based Assessment of the Scientific Research Literature on Reading and its Implications for Reading Instruction; National Institute for Literacy at EDPubs: Jessup, MD, USA, 2000.

47. National Early Literacy Panel. Developing Early Literacy: Report of the National Early Literacy Panel-A Scientific Synthesis of Early Literacy Development and Implications for Interventions; The Institute for Literacy and National Center for Family Literacy: Washington, DC, USA, 2008.

48. McIntyre, E. Sociocultural perspectives on children with reading difficulties. In Handbook of Reading Disability Research; McGill-Franzen, A., Allington, R., Eds.; Routledge: New York, NY, USA, 2011; pp. 45-56.

49. Hayes, J. A new framework for understanding cognition and affect in writing. In Theoretical Models and Processes of Reading, 5th ed.; Ruddell, R., Unrau, N., Eds.; International Reading Association: Newark, DE, USA, 2004; pp. 1399-1430.

50. Joshi, R.M.; Aaron, P.G. Componential model of reading (CMR): Validation studies. J. Learn. Disabil. 2012, 45, 387-390. [CrossRef]

51. Vellutino, F.R.; Tunmer, W.E.; Jaccard, J.J.; Chen, R. Components of reading ability: Multivariate evidence for a convergent skills model of reading development. Sci. Stud. Read. 2007, 11, 3-32. [CrossRef]

52. Hoover, W.A.; Gough, P.B. The simple view of reading. Read. Writ. 1990, 28, 127-160. [CrossRef]

53. Bernstein, D.; Tiegerman-Farber, E. Language and Communication Disorders in Children, 6th ed.; Pearson: Boston, MA, USA, 2009.

54. Gleason, J.B.; Ratner, N.B. The Development of Language, 8th ed.; Pearson: Columbus, OH, USA, 2013.

55. LaSasso, C.; Crain, K.; Leybaert, J. (Eds.) Cued Speech and Cued Language for Deaf And Hard of Hearing Children; Plural Publishing: San Diego, CA, USA, 2010.

56. Paul, P.V. Language and Deafness, 4th ed.; Sudbury, M.A., Ed.; Jason \& Bartlett: San Diego, CA, USA, 2009. 
57. Wang, Y.; Trezek, B.J.; Luckner, J.L.; Paul, P.V. The role of phonology and phonological-related skills in reading instruction for students who are deaf or hard of hearing. Am. Ann. Deaf 2008, 153, 396-407. [CrossRef]

58. Catts, H.W.; Kamhi, A.G. The Connections Between Language and Reading Disabilities; Erlbaum: Mahwah, NJ, USA, 2005.

59. Storch, S.; Whitehurst, G. Oral language and code-related precursors to reading: Evidence from a longitudinal structural model. Dev. Psychol. 2002, 38, 934-947. [CrossRef] [PubMed]

60. Dickinson, D.; Golinkoff, R.; Hirsh-Pasek, K. Speaking out for language: Why language is central to reading development. Educ. Res. 2010, 39, 305-310. [CrossRef]

61. Wang, Y.; Paul, P.V.; Falk, J.L.; Jahromi, L.B.; Ahn, S. Predictors of English reading comprehension for children who are d/Deaf or hard of hearing. J. Dev. Phys. Disabil. 2017, 29, 35-54. [CrossRef]

62. Shanahan, T. The reading-writing relation: An exploratory multi-variate analysis. J. Educ. Psychol. 1984, 76, 466-477. [CrossRef]

63. Shanahan, T. Relations among oral language, reading, and writing development. In Handbook of Writing Research; MacArthur, C., Graham, S., Fitzgerald, J., Eds.; The Guilford Press: New York, NY, USA, 2006; pp. 171-183.

64. Shanahan, T.; Lomax, R. An analysis and comparison of theoretical models of the reading-writing relationship. J. Educ. Psychol. 1986, 78, 116-123. [CrossRef]

65. Shanahan, T.; Lomax, R. A developmental comparison of three theoretical models of the reading-writing relationship. Res. Teach. Engl. 1988, 22, 196-212.

66. Strassman, B.K.; Marashian, K.; Memon, Z. Teaching academic language to d/Deaf students: Does research offer evidence for practice? Am. Ann. Deaf 2019, 163, 501-533. [CrossRef]

67. Hirsch, E.D.; Kett, J.; Trefil, J. (Eds.) The New Dictionary of Cultural Literacy, 3rd ed.; Houghton Mifflin: Boston, MA, USA, 2002.

68. Adams, M. Beginning to Read: Thinking and Learning about Print; The M.I.T. Press: Cambridge, MA, USA, 1990.

69. Alqraini, F. Challenges of children who are d/Deaf and hard of hearing while learning to read. Int. J. Literacies 2019, 26, 23-32. [CrossRef]

70. Whitehurst, G.; Lonigan, C. Child development and emergent literacy. Child Dev. 1998, 68, 848-872. [CrossRef]

71. Whitehurst, G.; Lonigan, C. Emergent literacy: Development from preschoolers to readers. In Handbook of Early Literacy Research; Neuman, S., Dickinson, D., Eds.; The Guilford Press: New York, NY, USA, 2002; pp. 11-29.

72. Trezek, B.; Wang, Y.; Paul, P. Processes and components of reading. In Handbook of Deaf Studies, Language, and Education, 2nd ed.; Marschark, M., Spencer, P., Eds.; Oxford University Press: New York, NY, USA, 2011; Volume 1, pp. 99-114.

73. Piasta, S.; Wagner, R. Developing early literacy skills A meta-analysis of alphabet learning and instruction. Read. Res. Q. 2010, 45, 8-38. [CrossRef]

74. Harris, M. The impact of new technologies on the literacy attainment of deaf children. Top. Lang. Disord. 2015, 35, 120-132. [CrossRef]

75. Webb, M.-Y.L.; Lederberg, A.R.; Branum-Martin, L.; Connor, C.M. Evaluating the structure of early English literacy skills in deaf and hard-of-hearing children. J. Deaf Stud. Deaf Educ. 2015, 20, 343-355. [CrossRef] [PubMed]

76. Beal-Alvarez, J.; Lederberg, A.R.; Easterbrooks, S.R. Grapheme-phoneme acquisition of deaf preschoolers. J. Deaf Stud. Deaf Educ. 2012, 17, 39-60. [CrossRef] [PubMed]

77. Trezek, B.J.; Hancock, G.R. Implementing instruction in the alphabetic principle within a sign bilingual setting. J. Deaf Stud. Deaf Educ. 2013, 18, 391-408. [CrossRef]

78. Paul, P.V. In praise of doubt and systematic inquiry. Am. Ann. Deaf 2014, 159, 305-311. [CrossRef]

79. Paul, P. In praise of doubt and systematic inquiry: Conclusion. Am. Ann. Deaf 2015, 159, 387-392. [CrossRef]

80. Mayer, C.; Trezek, B.J. Is reading different for deaf individuals? Reexamining the role of phonology. Am. Ann. Deaf 2014, 159, 359-371. [CrossRef] 
81. Mayer, C.; Leigh, G. The changing context for sign bilingual education programs: Issues in language and the development of literacy. Int. J. Biling. Educ. Biling. 2010, 13, 175-186. [CrossRef]

82. Archbold, S. Deaf Education: Changed by Cochlear Implantation? University of Nijmegen Medical Centre: Nijmegen, The Netherlands, 2010. 